\title{
KONTEKSTUALISASI AYAT AL-QUR'AN DALAM MENGHADAPI FENOMENA HOAX
}

\author{
A'yun Masfufah \\ Magister Komunikasi dan Penyiaran Islam, Fakultas Dakwah dan Komunikasi \\ UIN Sunan Kalijaga Yogyakarta \\ Ayunmasfufah76@gmail.com
}

\begin{abstract}
The purpose of this study was to determine the phenomenon of hoax that is rife in society. Why is hoax news easily spread in the community and how is our attitude to face the phenomenon of hoax news according to Al-Qur'an verse An-Nur verse 11 and Al-Hujurat verse 6. This research takes a case study of the Papua riots that occurred in Manokwari and then spreads to various the peak area in Surabaya, officials and Community Organizations came to Papuan student dormitories with accusations of destroying the red and white flag. Later it was found that the cause was hoax news that was spread by Tri Susanti, a former Gerindra legislative candidate. The police have set Tri Susanti as a suspect and the government in order to block the spread of hoax news and expressions of hatred in West Papua to continue blocking internet access until normal situations. The author can also conclude that what is written in the verse An-Nur verse 11 and AlHujurat verse 6 can be applied to the case today. It turns out that in the Qur'an, it has been explained how to deal with the phenomena of hoax news. There are several ways to find out the truth of a news according to the Ministry of Communication and Information site, namely being careful with provocative titles, looking at news sources, checking the facts, authenticity of photos and following anti-hoax discussions.
\end{abstract}

Keywords: hoax news, social media, new media 
Komunike, Volume XII, No. 1 Juni 2020

\begin{abstract}
Abstrak
Tujuan penelitian ini adalah untuk mengetahui fenomena hoaxyang marak terjadi di masyarakat. Mengapa berita hoax mudah tersebar di masyarakat dan bagaimana sikap kita menghadapi fenomena berita hoax sesuai ayat Al-Qur'an surat An-Nur ayat 11 dan Al-Hujurat ayat 6. Penelitian ini mengambil studi kasus kerusuhan Papua yang terjadi di Manokwari kemudian menyebar ke berbagai daerah yang puncaknya di Surabaya, aparat dan Organisasi Masyarakat mendatangi asrama mahasiswa Papua dengan tuduhan telah melakukan pengrusakan terhadap bendera merah putih. Kemudian ditemukan bahwa penyebabnya adalah berita hoax yang disebarkan oleh Tri Susanti mantan Caleg Gerindra. Polisi sudah menetapkan Tri Susanti sebagai tersangka dan pemerintah demi menghalau penyebaran berita hoax dan ujaran kebencian di Papua Barat melanjutkan pemblokiran akses internet sampai situasi normal. Penulis juga dapat menyimpulkan bahwa apa yang dituliskan dalam surat An-Nur ayat 11 dan Al-Hujurat ayat 6 bisa diaplikasikan dengan kasus zaman sekarang. Ternyata dalam Al-Qur'an sudah dijelaskan bagaimana cara menyikapi fenomena kasus berita bohong (hoax). Ada beberapa cara untuk mengetahui kebenaran sebuah berita sesuai situs kemenkominfo yaitu hati-hati dengan judul provokatif, liat sumber berita, periksa fakta, keaslian foto dan mengikuti diskusi anti hoax.
\end{abstract}

Kata kunci: berita hoax, media sosial, new media 


\section{PENDAHULUAN}

Perkembangan teknologi sangat mempengaruhi segala aspek kehidupan manusia, salah satunya adalah media sosial. Dari laporan berjudul "Essential Insights Into Internet, Social Media, Mobile, and E-Commerce Use Around The World' yang diterbitkan tanggal 30 Januari 2018, dari total populasi Indonesia sebanyak 265,4 juta jiwa, pengguna aktif media sosialnya mencapai 130 juta dengan penetrasi 49 persen $^{1}$. Menurut penelitian yang dilakukan We Are Social, perusahaan media asal Inggris yang bekerja sama dengan Hootsuite, rata-rata orang Indonesia menghabiskan tiga jam 23 menit sehari untuk mengakses media sosial.

Indonesia adalah negara demokrasi, setiap warga negara diberi kebebasan menyampaikan pendapat. Namun di era media sosial sekarang ini hak bebas menyampaikan pendapat itu sering

\footnotetext{
${ }^{1}$ Wahyunanda Kusuma Pertiwi, "Riset Ungkap Pola Pemakaian Medsos Orang Indonesia", dalam https://kompas.com/tekno/read/2018/03/01/ 10340027/riset-ungkap-pola-pemakaian-
}

disalah gunakan. Media sosial adalah medium internet yang memungkinkan peng'guna merepresentasikan dirinya maupun berinteraksi, bekerjasama, berbagi, berkomunikasi dengan pengguna lain dalam bentuk ikatan sosial secara virtual $^{2}$. Media sosial sering digunakan sebagai rujukan ketika mencari berita terkini, sekarang jarang orang membaca koran untuk melihat berita yang terjadi hari itu karena lebih mudah membuka handphone atau komputer yang tersambung internet. Salah satu dampak media sosial adalah penyebaran berita hoax, berita yang belum terbukti kebenarannya tetapi sudah tersebar dan banyak dipercaya oleh masyarakat. Dalam kamus Oxford hoax diartikan sebagai a trick played on somebody for a joke: $v$ deceive somebody with a hoax; trik yang yang dimainkan kepada seseorang sebagai sebuah candaan:

medsos-orang-indonesia diakses pada 20 September 2019 pukul 03.29 WIB

${ }^{2}$ Nasrullah Rulli, Media Sosial:

Perspektif Komunikasi, Budaya, dan

Sosioteknologi (Bandung: Simbiosa Reatama Media, 2015), hlm. 11 
Komunike, Volume XII, No. 1 Juni 2020

menipu seseorang dengan hoax(pen $)^{3}$. Hoax juga bisa disebut tindakan mengaburkan informasi yang sebenarnya dengan cara membanjiri media dengan pesan yang salah agar bisa menutupi pesan yang sebenarnya ${ }^{4}$.

Penyebaran berita hoax ini biasanya dimanfaatkan oleh orang atau kelompok tertentu untuk memperoleh keuntungan. Berita hoax tidak hanya berdampak kesalahan informasi tetapi juga bisa menjatuhkan individu atau kelompok. Masyarakat Indonesia sebagian besar memang sudah kenal dengan internet terlebih sosial media tetapi banyak masyarakat yang belum paham bagaimana etika menggunakan media internet. Cepatnya arus informasi membuat masyarakat malas untuk mencari lebih jauh berita yang diperoleh, terpancing oleh judul berita yang provokatif langsung disebar luaskan tanpa membaca isi berita tersebut. Portal berita sering menggunakan

\footnotetext{
${ }^{3}$ Oxford university, oxford leaner's pocket dictionary (London; Oxford

University press, 2018) hlm. 211

${ }^{4}$ Indonesia Mendidik, 2016,

Kulwap: Melek Literasi di Era Digital.
}

judul yang provokatif untuk menarik pengunjung supaya tertarik mengklik berita tersebut, atau sering disebut clickbait.

Kasus yang menjadi perhatian publik beberapa waktu lalu adalah berita tentang kerusuhan papua. Mantan Caleg Gerindra bernama Tri Susanti menyebarkan berita hoax tentang perusakan bendera di Asrama Mahasiswa Papua di Surabaya. Dalam penelitian ini penulis akan melihat bagaimana kontekstualisasi ayat Al-Qur'an dalam menghadapi fenomena hoax dan bagaimana upaya media maupun pemerintah dalam menyeleseikan kasus tersebut.

\section{LITERATURE REVIEW}

Untuk mendukung peneltian ini dan menghindari kesamaan terhadap penelitian yang sudah ada sebelumnya, peneliti menelaah beberapa literature yang dapat dijadikan perbandingan sekaligus pendukung pembahasan di atas.

Retrived September 12, 2019 from Indonesia Mendidik: https://indonesiamendidik.com/tag/anti$\underline{\text { hoax }}$ 
Pertama, Jurnal Ilmu komunikasi Universitas Gunadarma yang berjudul "Analisis Penyebaran Berita Hoax di Indonesia" oleh M. Ravii Marwan dan Ahyad. Penelitian ini menggunakan metode deskriptif kualitatif untuk melihat dan mendeskripsikan data dan fakta yang terjadi tentang penyebaran hoax di media sosial. Hasil dari penelitian ini menunjukkan bahwa kemajuan teknologi menjadi faktor penentu karena pengguna bisa dengan mudah mengakses informasi melalui internet. Serta peran pemerintah guna menanggulangi penyebaran hoax juga sangat penting.

Kedua, skripsi yang berjudul "Fenomena Hoax di Media Sosial dalam Pandangan Hermeneutika" oleh Ilham Syaifullah (2018). Penelitian ini bertujuan untuk mengidentifikasi berita atau informasi palsu di media sosial. Menggunakan teori hermenuetika seperti Hans G. Gadamer dan Paul Ricoeur untuk menghindari kasus hoax. Mengutip beberapa ayat AlQur'an seperti An-Nur ayat 11 mengenai kebenaran dalam menerima sebuah berita. Hasil penelitian ini adalah dengan menggunakan metode hermeneutika, kita bisa mengindari berita hoax dengan cara memahami peristiwa tersebut berdasarkan pengalaman sendiri dan menganalisa berdasarkan sumber-sumber lain yang lebih terpercaya. Kemudian memahami makna asli penyebaran berita tersebut, sehingga kita bisa menghindari jika sifat berita tersebut bersifat tidak baik.

Ketiga, Jurnal Pekommas dengan judul "Interaksi Komunikasi Hoax di Media Sosial serta Antisipasinya” oleh Cristiany Juditha (2018). Penelitian ini menggunakan pendekatan kualitatif dengan tujuan untuk mendapatkan gambaran tentang interaksi komunikasi hoax di media sosial dan cara mengantisipasinya. Dengan studi kasus pada tiga kasus hoax yang beredar di masyarakat tentang pemerintahan Presiden Jokowi dan Gubernur Jakarta Ahok. Hasil penelitian ini mengungkapkan bahwa interaksi komunikasi dibangun secara dinamis. Pengirim dan 
penerima berita hoax adalah orang yang tidak menyukai pemerintah. Penerima berita lain adalah yang tidak sepakat dan membantah berita hoax tersebut sebagai bukti dukungan kepada pemerintah. Ada tiga pendekatan yang bisa digunakan dalam menghadapi berota hoax yaitu kelembagaan, teknologi dan literasi.

\section{METODE PENELITIAN}

Dalam penelitian ini penulis menggunakan metode penelitian deskriptif kualitatif yaitu penelitian yang tidak mengadakan perhitungan, maksudnya data yang dikumpulkan tidak berwujud angka tetapi katakata. ${ }^{5} \quad$ Penelitian sosial menggunakan metode ini bertujuan untuk menggambarkan, meringkas berbagai kondisis, situasi dan fenomena realitas sosial di masyarakat. ${ }^{6}$ Peneliti menggunakan metode ini untuk mendeskripsikan, menguraikan, dan menggambarkan tentang kontekstualisasi Al-Qur'an

${ }^{5}$ Lexy J Moeleong, Metodologi Penelitian Kualitatif, (Bandung: PT. Remaja Rosdakarya, 2002), Hlm. 6 ${ }^{6}$ Burhan Bungin, Penelitian Kualitatif, (Jakarta: Kencana, 2008), hlm 68. dalam menghadapi fenomena hoax yang beredar di masyarakat.

\section{Teks Al-qur'an Tentang Hoax}

Dalam ayat Al-Qur'an surat An-Nur ayat 11 dan surat AlHujurat ayat 6 dijelaskan mengenai kebenaran dalam menerima berita dan bagaimana cara menerima suatu berita $^{7}$ :

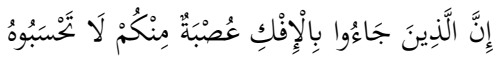

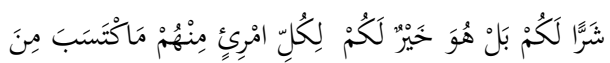

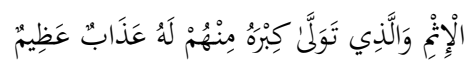

Artinya: Sesungguhnya orang-orang yang membawa berita bohong itu adalah dari golongan kamu juga. Janganlah kamu kira bahwa berita bohong itu buruk bagi kamu bahkan ia adalah baik bagi kamu. Tiap-tiap seseorang dari mereka mendapat balasan dari dosa yang dikerjakannya. Dan siapa di antara mereka yang mengambil bahagian yang terbesar dalam

\footnotetext{
${ }^{7}$ Tafsirweb,"Qur'an Surat An-Nur Ayat 11", dalam https://tafsirweb.com/6139-surat-an-nurayat-11.html diakses pada tanggal 21 September 2019 pada pukul 07.12 WIB
} 
penyiaran berita bohong itu baginya azab yang besar. (QS. An-Nur: 11)

Dalam surat An-Nur ayat 11 dijelaskan bahwa orang yang membawa berita bohong atau berita buruk itu sesama manusia dan akan mendapat balasan atas perbuatan mereka. Apabila terus menerus menyebarkan berita bohong orang tersebut akan menerima azab yang besar. Dalam tafsir Al-Misbah Ayat di atas menjelaskan mengenai kasus yang menimpa keluarga Nabi Muhammad SAW. Ayat ini mengecam kepada mereka yang menuduh istri Nabi 'Aisyah RA tanpa adanya bukti yang jelas. Allah berfirman:

"Sesungguhnya orang-orang
yang membawa yakni
menyebarluaskan dengan sengaja
berita bohong yang keji
menyangkut keluarga Nabi
Muhammad adalah golongan
yang dianggap bagian dari
komunitas kamu yakni yang
hidup ditengah kamu wahai kaum
mukminin. Janganlah kamu
menganggapnya yakni
menganggap berita bohong itu
buruk bagi kamu bahkan ia

${ }^{8}$ M. Quraish Shihab, Tafsir AlMisbah: Pesan, Kesan, dan Keserasihan AlQur'an, Jilid 9 (Ciputat: Lentera Hati cetakan IV. 2011), Hlm. 294 adalah baik bagi kamu karena dengan demikian kamu dapat membedakan siapa yang munafik dan siapa yang kuat imannya. Tiap-tiap seseorang dari mereka yang menyebarluaskan rumor itu memperoleh balasan sesuai kadar apa yang dengan sengaja dan sungguh-sungguh dia kerjakan dari dosa isu buruk itu. Dan siapa yang mengambil bagian terbesar yakni dalam penyiaran berita bohong itu, di antara mereka yang menyebarkannya maka baginya azab yang besar di akhirat nanti. ${ }^{9}$

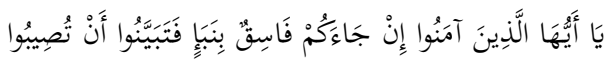

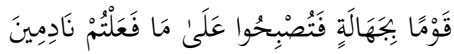

Artinya: Hai orang-orang yang beriman, jika datang kepadamu orang fasik membawa suatu berita, maka periksalah dengan teliti agar kamu tidak menimpakan suatu musibah kepada suatu kaum tanpa mengetahui keadaannya yang menyebabkan kamu menyesal atas perbuatanmu itu.(QS. Al-Hujurat: $6)^{10}$

Sedangkan dalam surat AlHujarat ayat 6 menjelaskan bagaiamana orang-orang yang

${ }^{9}$ M. Quraish Shihab, Tafsir AlMisbah: Pesan, Kesan, dan Keserasihan AlQur'an, Jilid 9 (Ciputat: Lentera Hati cetakan IV. 2011), Hlm. 294-295

${ }^{10}$ Ibid, Hlm. 587 
Komunike, Volume XII, No. 1 Juni 2020

beriman menghadapi orang fasik yang membawa suatu berita. Kita harus teliti ketika memeriksa berita, dilihat dulu fakta dari berita tersebut dan apakah sumbernya terpercaya supaya tidak menyesal dan tertimpa masalah gara-gara mempercayai suatu berita tanpa memeriksa kebenarannya. Dalam tafsir AlMisbah dijelaskan bahwa ayat di atas:

Menggunakan kata (إن) in/jika yang biasanya digunakan untuk sesuatu yang diragukan atau jarang terjadi. Ini mengisyaratkan bahwa kedatangan seorang fasik kepada orang-orang beriman diragukan atau jarang terjadi. Hal ini disebabkan orang-orang fasik mengetahui bahwa kaum beriman tidak mudah dibohongi dan bahwa mereka akan meneliti kebenaran setiap informasi sehingga sang fasik dapat dipermalukan dengan kebohongannya. Kata (فاسق) fasik diambil dari kata fasaqa yang biasa digunakan untuk melukiskan buah yang telah rusak atau terlalu matang sehingga terkelupas kulitnya. Seseorang yang durhaka adalah orang yang keluar dari koridor agama akibat melakukan dosa besar atau sering kali melakukan dosa kecil. Kata (نبأ) Naba' digunakan dalam arti berita yang penting. Berbeda dengan

${ }^{11}$ M. Quraish Shihab, Tafsir AlMisbah: Pesan, Kesan, dan Keserasihan Al- kata (خبر) khabar yang berarti

kabar secara umum, baik penting maupun tidak. Dari sini, terlihat perlunya memilih informasi apakah penting atau tidak dan memilah informasi apakah dapat dipercaya atau tidak. Orang beriman tidak dituntut untuk menyelidiki kebenaran informasi dari siapa pun yang tidak penting, bahkan didengarkan tidak wajar, karena jeika demikian akan banyak energi dan waktu yang dihamburkan untuk hal-hal yang tidak penting. Kata ( بكها لة) bi jahalah berarti tidak mengetahui dan dapat juga diartikan serupa dengan makna kejahilan, yakni perilaku seseorang yang kehilangan kontrol dirinya sehingga melakukan hal-hal tidak wajar. Baik atas dorongan nafsu, kepentingan sementara, maupun kepicikan pandangan. Istilah ini juga digunakan dalam arti mengabaikan nilai-nilai ajaran ilahi. ${ }^{11}$

Ayat di atas menjadi salah satu dasar yang ditetapkan oleh agama untuk diterapkan dalam kehidupan sosial. Bisa juga menjadi cara untuk berfikir logis ketika menerima suatu berita. Karena kemampuan manusia yang tidak dapat menjangkau informasi secara menyeluruh maka membutuhkan orang lain untuk mengkonfirmasi

Qur'an, Jilid 9 (Ciputat: Lentera Hati cetakan IV. 2011), Hlm. 588-589 
berita tersebut. Tetapi harus berhatihati juga dengan sumber berita atau pihak yang dijadikan referensi berita, harus melihat kejujuran dan integritas pihak tersebut sebelum mempercayainya. Ayat di atas mengajarkan kita untuk berfikir logis dan berdasarkan ilmu pengetahuan untuk melawan kebodohan. Ayat di atas juga mencontohkan dahulu ketika para ulama' menyeleksi informasi para perawi hadits-hadits Nabi, salah satu yang dibahas adalah penerimaan riwayat yang disampaikan oleh sejumlah orang yang dinilai mustahil menurut kebiasaan mereka sepakat berbohong atau istilahnya disebut mutawatir. Ini diakui oleh semua pakar, jumlah yang banyak itu harus memenuhi syarat-syarat. Dengan kata lain meskipun banyak yang menyampaikan tidak menjamin kalo itu benar. Seperti berita, meskipun banyak sekali yang menyebarkan berita tersebut belum tentu pesan yang disampaikan benar.

\section{Kontekstualisasi Teks Al-Qur'an Studi Kasus}

Idntimes.com memuat berita tentang kronologis Kerusuhan Papua yang menyeret wilayah lain pada tanggal 20 Agustus 2019. Aksi unjuk rasa pertama kali dilakukan di Manokwari, Papua Barat oleh warga pada hari senin 19 Agustus 2019 sebagai bentuk protes atas tindakan kekerasan yang diduga dilakukan oleh oknum aparat kepada mahasiswa Papua di jawa Timur. Kericuhan di Manokwari terjadi saat mahasiswa berunjuk rasa untuk memperingati Perjanjian New York 1962 tanggal 15 Agustus 2019, aksi ini dilakukan di sejumblah daerah. Aksi tersebut tidak disambut dengan baik oleh aparat karena tidak memperoleh izin seperti di Jayapura, Sentani, Malang, Ternate, Ambon, Sula dan Bandung.

$$
\text { Hanya di Jakarta dan }
$$
Yogyakarta aksi tersebut berjalan tertib. Kemudian sehari setelah aksi tersebut asrama mahasiswa Papua di Surabaya didatangi oleh aparat dan organisasi massa yang tidak jelas identitasnya dengan alasan telah terjadi pengrusakan bendera merah putih di asrama tersebut. Aparat dan 
ormas diduga melakukan intimidasi dan melontarkan kata-kata rasis kemudian melakukan pengusiran kepada 43 mahasiswa asal Papua dan digiring ke kantor polisi. Kabar inilah yang memicu kerusuhan selanjutnya, masyarakat meminta kepada pemerintah untuk mengambil tindakan dan menindak tegas apabila terbukti ada penganiayaan dan intimidasi ${ }^{12}$.

\section{Analisis}

Setelah membaca kronologi kasus kerusuhan yang terjadi Papua penulis mencari sebab utama kenapa kerusuhan itu semakin membesar. Ternyata penyebab asrama mahasiswa Papua yang berada di Surabaya didatangi oleh aparat dan ormas itu dipicu oleh berita hoax yang mengatakan bahwa telah terjadi pengrusakan bendera merah putih, dimasukkan selokan dan dipatahpatahkan. Seperti diberitakan alinea.id Polda Jawa Timur menetapkan mantan Caleg Gerindra

\begin{tabular}{llr}
\hline \multicolumn{1}{c}{${ }^{12}$} & Fitang Budhi & Adhitia, \\
"Kronologis & Kerusuhan Papua & Yang \\
Menyeret & Wilayah Lain", & dalam \\
https://idntimes.com/news/indonesia/fitang-- & diakses \\
adhitia/kronologis-kerusuhan-papua & diaks \\
pada tanggal 21 September 2019 pada pukul \\
05.44 WIB
\end{tabular}

Tri Susanti sebagai tersangka karena mengerahkan massa dan provokasi dengan menyebar informasi hoax hingga terjadi kerusuhan. Tidak sampai disitu Kasubdit Cyber Crime Ditreskimsus Polda Jatim AKBP Cecep Susatya juga menemukan ujaran kebencian kepada mahasiswa Papua dalam pesan yang dikirim kepada orang-orang. Tri Susanti dianggap melanggar UndangUndang tentang ITE dan Pasal KUHP $160^{13}$.

Kasus tersebut sesuai dengan asumsi teori media baru yaitu integrasi sosial bahwa media diritualkan karena menjadi kebiasaan dan tuntutan waktu. Arus informasi yang sangat cepat menyebabkan orang tidak berhatihati dalam menerima informasi karena sudah terbiasa mempercayai apa yang disebarkan melalui media sosial dan tidak punya waktu untuk memeriksa fakta dari berita tersebut. Teori persamaan media memprediksi

13 Adi Suprayitno, "Cara Caleg Gerindra Tri Susanti Sebar Hoax Papua di Surabaya", dalam https://alinea.id/nasional/cara-caleggerindra-tri-susanti-sebar-hoax-papua/disurabaya diakses pada tanggal 21 September 2019 pada pukul 06.28 WIB 
bahwa secara tidak sadar seseorang merespon suatu berita seolah-olah orang yang menyampaikan berita tersebut sedang berbicara dengannya kemudian langsung mempercayainya padahal berita yang disampaikan melalui media sosial belum diperiksa sumber beritanya dan fakta berita tersebut.

Tri Susanti menyebarkan berita melalui pesan Whatsapp bahwa mahasiswa Papua melakukan pengrusakan terhadap bendera merah putih dan menyebarkan ujaran kebencian dengan mengatakan mahasiswa Papua akan menyerang menggunakan senjata tajam dan panah, dari dua pesan yang dia sebarkan itu ternyata berita tidak benar atau hoax. Tetapi berita hoax itu berhasil mempengaruhi aparat dan organisai masyarakat untuk mendatangi asrama mahasiswa Papua untuk mengintimidasi mereka.

Tri Susanti sudah ditetapkan sebagai tersangka oleh pihak

14 Henri Septanto, "Pengaruh HOAX dan Ujaran Kebencian Sebuah Cyber Crime Dengan Teknologi Sederhana di Kehidupan Sosial Masyarakat”, Jurnal kepolisian, ini seperti yang dikatan di surat An-Nur ayat 11 bahwa orang yang membawa berita bohong atau berita buruk itu sesama manusia dan akan mendapat balasan atas perbuatan mereka. Apabila terus menerus menyebarkan berita bohong orang tersebut akan menerima azab yang besar. Sebaik-baiknya manusia menutupi kesalahannya pasti akan terungkap kemudian hari, apalagi menyebabkan kerugian banyak orang.

Berita hoax digunakan sebagai alat untuk mempengaruhi publik, baik untuk kepentingan individidu maupun kelompok. Stimulan terbesar dalam penyebaran berita hoax adalah SARA dan politik $^{14}$. Kedua stimulan tersebut sangat mudah untuk memancing reaksi masyarakat karena sangat dekat dengan kehidupan sehari-hari belum lagi beragamnya budaya dan suku yang ada di Indonesia maka isu SARA sangat sensitif. Menurut penelitian

Sirverman 
mengungkapkan sebuah rumor yang disebar secara terus-menerus lama kelamaan akan dianggap masuk akal dan diyakini sebagai kebenaran dan bisa mengubah opini masyarakat ${ }^{15}$.

CNBC Indonesia memuat berita bahwa kementrian Komunikasi dan Informatika (Kemenkominfo) memutuskan untuk melanjutkan pemblokiran data internet pada layanan seluler di Papua dan Papua Barat ${ }^{16}$. Langkah ini dilakukan guna menghambat penyebaran berita hoax, ujaran kebencian, provokatif dan rasis di daerah Papua. Pemblokiran ini hanya untuk jaringan internet, masyarakat masih bisa berkomunikasi melalui telpon, karena tidak bisa mengatur penyebaran berita hoax maka pemerintah mengambil cara memperlambat media penyebaran berita tersebut. Meskipun menuai

15 Christiany Juditha, "Interaksi Komunikasi Hoax di Media Sosial serta Antisipasinya Hoax Communication Interactivity in Social Media and Anticipation”, Puslitbang Aplikasi Informatika dan Informasi Komunikasi Publik Kementerian Komunikasi dan Informatika RI, Jurnal Pekommas, Vol. 3 No. 1, April 2018, hlm. 38 banyak protes dari berbagai kalangan karena dinilai membungkam suara rakyat tapi ini hanya berlangsung sampai keadaan kembali normal.

$$
\text { Untuk mengidentifikasi }
$$

kebenaran sebuah berita dan terhindar dari berita hoax Kemenkominfo memberikan langkah-langkahnya sebagai berikut, pertama hati-hati dengan judul yang provokatif karena judul provokatif biasanya hanyak untuk mengundang clickbait supaya banyak yang mengklik halaman beritanya padahal isi beritanya belum tentu berkaitan dengan judulnya. Kedua, cermati alamat situs asal beritanya, semakin situs beritanya tidak jelas jangan langsung percaya dengan berita yang ditulis lebih baik memeriksa di situs berita yang terpercaya. Ketiga, periksa fakta dengan cara membandingkan berita yang kita

${ }^{16}$ Houtmand P Saragih, "Banyak Hoax, Blokir Internet di Papua \& Papua Barat Berlanjut", dalam https://cnbcindonesia.com/news/banyakhoax-blokir-internet-di-papua-baratberlanjut/ diakses pada tanggal 20 September pada pukul 08.07 WIB 
peroleh dengan berbagai sumber berita yang lain. Keempat, apabila beritanya memuat foto cek kembali apakah foto itu asli atau hanya editan. Terakhir adalah mengikuti diskusi-diskusi anti hoax untuk menambah wawasan supaya tidak terpengaruh berita hoax.

Ada cara lagi solusi supaya tidak terjebak berita hoax sesuai dengan pedoman $\mathrm{Al}$-Qur'an surat $\mathrm{Al}$ Hujurat ayat 6 yaitu berfikir logis dan kritis terhadap segala sesuatu, kematangan emosi yang artinya tidak mudah terpancing emosinya apabila membaca sebuat berita, tabayyun dan menambah wawasan supaya fikirannya terbuka. Dan selalu ingat bahwa meskpun berita itu banyak sekali orang yang menyebar luaskan belum tentu pesan yang disampaikan benar. Selalu periksa dulu fakta dan cari dari berbagai sumber berita sebelum mempercayai sebuah berita.

\section{KESIMPULAN}

Dari pembahasan di atas peneliti dapat menyimpulkan bahwa apa yang dituliskan dalam surat AnNur ayat 11 dan Al-Hujurat ayat 6 bisa diaplikasikan dengan kasus zaman sekarang. Dalam Al-Qur'an sudah dijelaskan cara menyikapi fenomena kasus berita bohong (hoax), menjelaskan langkahlangkah supaya tidak terjerumus berita bohong dan berhati-hati supaya tidak menjadi pelaku penyebar hoax. Menyebarkan berita yang belum tentu kebenarannya bisa menjadikan kita orang fasik dan akan mendapatkan azab yang besar. Pemerintah juga berhasil menangkap tersangka yang menyebarkan berita hoax dan ujaran kebencian, serta mengumpulkan bukti-bukti untuk memproses kasus ini lebih lanjut. Kemenkominfo melanjutkan pemblokiran internet di Papua sampai situasi kembali normal untuk menghalau penyebaran berita hoax dan ujaran kebencian lebih luas lagi. Di laman kemenkominfo juga menyediakan informasi langkahlangkah menghindari berita hoax supaya masyarakat punya bekal tidak mudah terpancing dengan berita yang belum tentu kebenarannya.

\section{DAFTAR PUSTAKA}


Komunike, Volume XII, No. 1 Juni 2020

Lexy J Moeleong, Metodologi Penelitian Kualitatif, (Bandung: PT Remaja Rosdakarya, 2002).

M. Quraish Shihab, Tafsir AlMisbah: Pesan, Kesan, dan Keserasihan Al-Qur'an, Jilid 9, (Ciputat: Lentera Hati cetakan IV, 2011).

M. Quraish Shihab, Tafsir AlMisbah: Pesan, Kesan, dan Keserasihan Al-Qur'an, Jilid 12, (Ciputat: Lentera Hati cetakan IV, 2011).

Oxford university, Oxford Leaner's Pocket Dictionary, (London: Oxford University press, 2018).

Rulli Nasrullah, Komunikasi antarbudaya di Era Budaya Siber,(Jakarta: Kencana Prenada Media Group, 2012).

Rulli Nasrullah, Media Sosial: Perspektif Komunikasi, Budaya, dan Sosioteknologi, (Bandung: Simbiosa Reatama Media, 2015).

Christiany Juditha, Interaksi Komunikasi Hoax di Media Sosial serta Antisipasinya Hoax Communication Interactivity in Social Media and Anticipation (Puslitbang Aplikasi Informatika dan Informasi Komunikasi Publik Kementerian Komunikasi dan Informatika RI, Jurnal Pekommas, Vol. 3 No. 1, April 2018)

Gumgum Gumilar, Justito Adiprasetio dan Nunik
Maharani, Literasi Media: Cerdas Menggunakan Media Sosial dalam Menanggulangi Berita Palsu (HOAX) oleh Siswa SMA (Jurnal Pengabdian Kepada Masyarakat: Fakultas Ilmu Komunikasi Universitas Padjajaran, Vol. 1, No. 1, Februari 2017)

Henri Septanto, Pengaruh HOAX dan Ujaran Kebencian Sebuah Cyber Crime Dengan Teknologi Sederhana di Kehidupan Sosial Masyarakat, (Jurnal Sains dan Teknologi, CALBISienta Institut Teknologi Informatika dan Bisnis Kalbis, volume 5 No. 2 Agustus 2018)

Adi Suprayitno, "Cara Caleg Gerindra Tri Susanti Sebar Hoax Papua di Surabaya”, dalam

https://alinea.id/nasional/cara -caleg-gerindra-tri-susantisebar-hoax-papua/disurabaya (21 September 2019)

Fitang Budhi Adhitia, "Kronologis Kerusuhan Papua Yang Menyeret Wilayah Lain", dalam

https://idntimes.com/news/in donesia/fitangadhitia/kronologiskerusuhan-papua September 2019).

Indonesia Mendidik, "Kulwap: Melek Literasi di Era Digital" dalam https://indonesiamendidik.co 
Komunike, Volume XII, No. 1 Juni 2020

$\underline{\mathrm{m} / \text { tag } / \text { anti-hoax }}$

$(12$

September 2019).

Tafsirweb,"Qur'an Surat An-Nur Ayat 11", dalam

https://tafsirweb.com/6139-

surat-an-nur-ayat-11.html

(21 September 2019).

\begin{tabular}{l}
\multicolumn{2}{c}{ Wahyunanda Kusuma } \\
Pertiwi, "Riset Ungkap $\begin{array}{r}\text { Pola } \\
\text { Orang } \\
\text { Pemakaian Medsos }\end{array}$ \\
Indonesia", \\
https://kompas.com/tekno/read/2018 \\
\hline /03/01/10340027/riset-ungkap-pola- \\
\hline pemakaian-medsos-orang-indonesia \\
(20 September 2019).
\end{tabular}

